\title{
Inhibition of allergic airway responses by heparin derived oligosaccharides: identification of a tetrasaccharide sequence
}

\author{
Tahir Ahmed', Gregory Smith¹, Iontcho Vlahov² and William M Abraham*
}

\begin{abstract}
Background: Previous studies showed that heparin's anti-allergic activity is molecular weight dependent and resides in oligosaccharide fractions of $<2500$ daltons.

Objective: To investigate the structural sequence of heparin's anti-allergic domain, we used nitrous acid depolymerization of porcine heparin to prepare an oligosaccharide, and then fractionated it into disaccharide, tetrasaccharide, hexasaccharide, and octasaccharide fractions. The anti-allergic activity of each oligosaccharide fraction was tested in allergic sheep.
\end{abstract}

Methods: Allergic sheep without (acute responder) and with late airway responses (LAR; dual responder) were challenged with Ascaris suum antigen with and without inhaled oligosaccharide pretreatment and the effects on specific lung resistance and airway hyperresponsiveness (AHR) to carbachol determined. Additional inflammatory cell recruitment studies were performed in immunized ovalbumin-challenged BALB/C mice with and without treatment.

Results: The inhaled tetrasaccharide fraction was the minimal effective chain length to show anti-allergic activity. This fraction showed activity in both groups of sheep; it was also effective in inhibiting LAR and AHR, when administered after the antigen challenge. Tetrasaccharide failed to modify the bronchoconstrictor responses to airway smooth muscle agonists (histamine, carbachol and $\mathrm{LTD}_{4}$ ), and had no effect on antigen-induced histamine release in bronchoalveolar lavage fluid in sheep. In mice, inhaled tetrasaccharide also attenuated the ovalbumininduced peribronchial inflammatory response and eosinophil influx in the bronchoalveolar lavage fluid. Chemical analysis identified the active structure to be a pentasulfated tetrasaccharide ([IdoU2S $(1 \rightarrow 4)$ GlcNS6S $(1 \rightarrow 4)$ IdoU2S $(1 \rightarrow 4)$ AMan-65]) which lacked anti-coagulant activity.

Conclusions: These results demonstrate that heparin tetrasaccharide possesses potent anti-allergic and antiinflammatory properties, and that the domains responsible for anti-allergic and anti-coagulant activity are distinctly different.

\section{Introduction}

Heparin is a highly sulfated, linear polysaccharide that has multiple biological activities [1-3]. Heparin inhibits blood coagulation [1], but also has numerous "non-anticoagulant" functions, including interaction with various growth factors $[4,5]$, modulation of cellular proliferation $[6,7]$ and regulation of angiogenesis [8]. Heparin also

\footnotetext{
* Correspondence: abraham@msmc.com

'Department of Research, Mount Sinai Medical Center, Miami Beach, Florida, USA

Full list of author information is available at the end of the article
}

modulates various proteases and enzymes [9-11] and possesses anti-inflammatory and immunoregulatory activities [12-14]. Thus, inhaled heparin has been shown to inhibit allergic airway responses in sheep [15], as well as to prevent the bronchoconstrictor responses to exercise and antigen in asthmatic subjects [16-19]. Many biological actions of heparin, including the anticoagulant and the anti-allergic activity are molecular weight dependent [20-22]. In allergic sheep, an inverse relationship between molecular weight and the anti-allergic activity of fractionated heparin was observed, with ultralow
C Biomed Central

C 2012 Ahmed et al; licensee BioMed Central Ltd. This is an Open Access article distributed under the terms of the Creative Commons Attribution License (http://creativecommons.org/licenses/by/2.0), which permits unrestricted use, distribution, and reproduction in any medium, provided the original work is properly cited. 
molecular weight heparin found to be the most potent fraction [21-23].

The basic polymeric structure of glycosaminoglycan heparin is an alternating sequence of disaccharide units comprising of repeating $1 \rightarrow 4$ linked L-iduronic acid and $\mathrm{D}$-glucosamine residues $[2,3]$. The sugar sequence, degree of sulfation and its high charge density are the basis of heterogenous molecular organization of heparin and its ability to interact with various proteins causing their activation, deactivation, or stabilization $[2,3,24]$. Heparin's structural heterogeneity is linked to its multiplicity of actions. For example, the binding domain to antithrombin III [25], and basic fibroblast growth factor [4] demonstrate the relationship between the fine structure of heparin derived oligosaccharides and biological functions. The antithrombin III binding site requires a minimal pentasaccharide sequence [25], while the binding domain to basic fibroblast growth factor requires a hexasaccharide sequence [4].

Consistent with these observations, our previous studies have demonstrated that the anti-allergic activity of heparin is independent of its anti-coagulant properties and resides in oligosaccharide fractions ( $<2500$ daltons) [23]. However, the exact structural sequence is not known. Therefore, the purpose of this study was to identify the minimal chain length and structural sequence of the anti-allergic domain of heparin. To do this, we prepared an oligosaccharide mixture, used sizeexclusion chromatography to obtain disaccharide, tetrasaccharide, hexasaccharide and octasaccharide fractions, and then determined their anti-allergic activity.

\section{Methods \\ Ovine Studies \\ Animal Preparation}

All procedures used in this study were approved by the Mount Sinai Animal Research Committee, which is responsible for ensuring the humane care and use of experimental animals. Twenty unsedated adult female sheep, with an average weight of $31 \mathrm{~kg}(27-36 \mathrm{~kg})$, were suspended in an upright position in a specialized body harness in a modified shopping cart, with their heads secured as published previously [26,15]. All sheep were allergic to Ascaris suum antigen and had previously been shown to develop bronchoconstriction following inhalation challenge with the antigen, either without (acute responders) or with late airway responses (dual responders) [27].

\section{Airway Mechanics}

Measurements of mean pulmonary airflow resistance, in units of $\mathrm{cm} \mathrm{H}_{2} \mathrm{O} / \mathrm{L} / \mathrm{s}$, and thoracic gas volume, in liters, were made by the esophageal balloon technique and body plethysmography, respectively, as previously described $[27,15]$. Data were expressed as specific lung resistance $\left(\mathrm{SR}_{\mathrm{L}}=\right.$ mean pulmonary airflow resistance $\times$ thoracic gas volume) in $\mathrm{cmH}_{2} \mathrm{O} / \mathrm{sec}$.

\section{Aerosol Delivery System}

All aerosols were generated using a disposable medical nebulizer (Raindrop, Puritan Bennett, Lenexa, KS). The nebulizer was connected to a dosimeter system consisting of a solenoid valve and a source of compressed air. The output of the nebulizer was directed into a plastic t-piece, which was interconnected between the inspiratory port of the Harvard animal respirator and the endotracheal tube. The solenoid valve was activated for $1 \mathrm{sec}$ at the beginning of the inspiratory cycle of the respirator. Aerosols were delivered at a tidal volume of $500 \mathrm{ml}$ and a rate of 20 breaths/minute. Various heparin oligosaccharide fractions were dissolved in $3 \mathrm{ml}$ of bacteriostatic injection water and administered as an aerosol over 15-20 minutes. Aerosols of Ascaris suum extract (diluted 20:1 with phosphate buffered saline; 82000 protein nitrogen units $/ \mathrm{ml}$ ) and carbachol were also generated with this nebulizer system.

\section{Bronchial Reactivity to Carbachol}

To assess baseline airway responsiveness, cumulative dose-response curves to inhaled carbachol were performed on experiment day 1 by measuring $\mathrm{SR}_{\mathrm{L}}$, before and immediately after inhalation of buffered saline and after each administration of 10 breaths of increasing concentrations of carbachol $(0.25 \%, 0.5 \%, 2.0 \%, 3.0 \%$ and $4.0 \% \mathrm{wt} / \mathrm{vol}$ solution). The bronchoprovocation was discontinued when $\mathrm{SR}_{\mathrm{L}}$ increased to $400 \%$ above the baseline. The cumulative provocating dose of carbachol (in breath units) that increased $\mathrm{SR}_{\mathrm{L}}$ to $400 \%$ above the baseline was calculated $\left(\mathrm{PD}_{400}\right)$. One breath unit was defined as one breath of $1 \%$ carbachol solution. Baseline dose-response curves to carbachol were performed in all sheep at least 2 weeks after the last exposure to antigen $[27,15,28]$.

\section{Bronchoalveolar Lavage (BAL)}

The distal tip of a specifically designed $80 \mathrm{~cm}$ fiberoptic bronchoscope was wedged into a randomly selected subsegmental bronchus. BAL was performed by an infusion and gentle aspiration of $30 \mathrm{ml}$ aliquots of phosphate buffered saline $(\mathrm{pH} 7.4)$ at $39^{\circ} \mathrm{C}$, using $30 \mathrm{ml}$ syringes attached to the working channel of the bronchoscope. The effluent was filtered through a single layer of gauze and placed immediately on ice. The volume of the effluent collected from the BAL fluid was measured and centrifuged at $420 \mathrm{~g}$, at $4^{\circ} \mathrm{C}$ for 15 minutes. The supernatant was decanted and centrifuged again at $1000 \mathrm{~g}$, at $4{ }^{\circ} \mathrm{C}$ for 15 minutes. The supernatant was frozen at $-80^{\circ} \mathrm{C}$ for subsequent histamine analysis.

\section{Histamine Radioimmunoassay}

Duplicate aliquots from each BAL sample were used for histamine radioimmunoassay using a commercial kit from Immunotech International (AMAC Inc; Westerbrook, 
$\mathrm{ME}$ ). The sensitivity of the assay is $0.05-2.0 \mathrm{nM}$, and coefficient of variation is $<10 \%$. There is less than $0.1 \%$ crossreactivity with histidine, serotonin or t-methyl histamine.

\section{Murine Studies}

These studies were also approved by the Mount Sinai Animal Research Committee. Female BALB/c mice, 4-6 weeks old were immunized by injecting intra-peritoneally with $0.2 \mathrm{ml}$ of $0.05 \%$ solution of ovalbumin adsorbed to alum on day 1 and again on day 14 . On days $25,26, \& 27$, the animals were placed in an exposure chamber for ovalbumin aerosol challenge (3\% ovalbumin for 30 minutes). Aerosols were generated using a PARi IS-2 nebulizer at a flow rate of $6 \mathrm{l} / \mathrm{min}$. 24 hours later, on day 28 , the mice were sacrificed, the trachea was carefully dissected and a blunt needle was inserted. Bronchoalveolar lavage (BAL) was performed with freshly prepared phosphate buffered saline $(\mathrm{PBS}, 0.8 \mathrm{ml})$ at $4^{\circ} \mathrm{C}$. The BAL fluid was centrifuged at 1500 RPM for 10 minutes. The supernatant was separated and the pellet was resuspended in PBS to a volume of $0.3 \mathrm{ml}$, and centrifuged again at 650 RPM for $10 \mathrm{~min}$ utes. The slides were prepared and stained with a GiemsaWright stain. In some mice, after the BAL was completed, the lungs were dissected, fixed in formalin and embedded in paraffin for histology. The tissues were cut into 3 um sections and stained with hematoxylin and eosin stain.

\section{Preparation of Heparin Oligosaccharides}

An aqueous solution of porcine intestinal heparin (USP) was depolymerized at room temperature with $\mathrm{HNO}_{2}$, generated in situ from $\mathrm{HCl}$ and $\mathrm{NaNO}_{2}$ (pH: 1.5). After one hour, the reaction $\mathrm{pH}$ was raised to 10 by addition of aqueous $\mathrm{NaOH}$. The solution was then reacted with $\mathrm{NaBH}_{4}$ for 18 hours to reduce the aldehyde group in the terminal 2,5-anhydro-D-mannose, obtained in the initial depolymerization step [29]. Reaction mixture was then neutralized and subjected to freeze-drying, which yielded the sodium salt of oligosaccharide mixture. Size exclusion gel chromatography of the oligosaccharide mixture was performed on $1.5 \mathrm{M} \times 80 \mathrm{~cm}$ column, containing BioRad P4 Biogel (10 L) and eluting with $0.2 \mathrm{M}$ $\mathrm{NH}_{4} \mathrm{HCO}_{3}$. After lyophilization, an ammonium salt of the appropriate fractions was obtained. The salt form was exchanged to sodium by passing the aqueous solution of the ammonium salt of each fraction through a column containing Amberlite 1R 120 PLUS cationexchange Resin (Sigma Aldrich Chemical Co.). Finally, after freeze-drying the sodium salt of each oligosaccharide fraction (i.e. disaccharide, tetrasaccharide, hexasaccharide and octasaccharide) was collected.

\section{Characterization of Heparin Oligosaccharides}

The size of the sodium salt of each heparin-derived oligosaccharide fraction, including disaccharide, tetrasaccharide, hexasaccharide and octasaccharide was determined by size exclusion HPLC [30]. Further structural confirmation of the disaccharide, tetrasaccharide, hexasaccharide fractions was obtained by ${ }^{1} \mathrm{H}-\mathrm{NMR},{ }^{13} \mathrm{C}-\mathrm{NMR}$, and Mass Spectrometry [30-32].

\section{Experimental Protocol \\ Ovine Studies:}

\section{A. Effect of Heparin Oligosaccharides in Acute Responders}

For the control experiment, after the baseline measurements of $S_{L}$, the sheep $(n=6)$ were challenged with aerosolized antigen and measurements of $\mathrm{SR}_{\mathrm{L}}$ were repeated within five minutes post-challenge. To evaluate the effect of heparin oligosaccharides on this antigen-induced response, dose-response studies were performed. The inhaled doses of various oligosaccharides used were: (a) oligosaccharide mixture $(\mathrm{n}=6) 0.25 \mathrm{mg} / \mathrm{kg}, 0.5 \mathrm{mg} / \mathrm{kg}$ and $1 \mathrm{mg} / \mathrm{kg}$; (b) octasaccharide $(\mathrm{n}=5), 0.125 \mathrm{mg} / \mathrm{kg}$, $0.25 \mathrm{mg} / \mathrm{kg}$, and $0.5 \mathrm{mg} / \mathrm{kg}$; (c) hexasaccharide $(\mathrm{n}=5)$, $0.03 \mathrm{mg} / \mathrm{kg}, 0.06 \mathrm{mg} / \mathrm{kg}$ and $0.125 \mathrm{mg} / \mathrm{kg}$; (d) tetrasaccharide $(\mathrm{n}=5), 0.03 \mathrm{mg} / \mathrm{kg}, 0.06 \mathrm{mg} / \mathrm{kg}$ and $0.125 \mathrm{mg} / \mathrm{kg}$; (e) disaccharide $(n=3)$ was evaluated only at a dose of $4 \mathrm{mg} / \mathrm{kg}$. The sheep were pretreated with different doses of oligosaccharides, 30 minutes before the antigen challenge and measurements of $\mathrm{SR}_{\mathrm{L}}$ were repeated within five minutes post antigen challenge. The interval between tests with each dose of the different oligosaccharide fractions was at least two weeks.

\section{B. Effect of Heparin Oligosaccharides in Dual Responders ( $n=6)$}

For every oligosaccharide tested, each sheep was studied on three different experiment days. For the control experiments, baseline bronchial reactivity to carbachol $\left(\mathrm{PD}_{400}\right)$ was determined on experiment day 1 . On experiment day 2, after the baseline measurements of $\mathrm{SR}_{\mathrm{L}}$, each animal was challenged with aerosolized Ascaris suum antigen. Repeat measurements of $\mathrm{SR}_{\mathrm{L}}$ were obtained within five minutes after the antigen challenge, and serially for up to eight hours for demonstration of early airway response (EAR) and late airway response (LAR). Twenty-four hours after the antigen challenge, bronchial reactivity to carbachol was re-determined (experiment day 3) as an index of antigeninduced airway hyperresponsiveness (AHR).

The above-mentioned 3-day protocol was repeated, at least two weeks apart for each dose of the oligosaccharide tested. In each sheep, the baseline $\mathrm{PD}_{400}$ of carbachol was determined on experiment day 1 , followed by experiment day 2 , when the sheep were pretreated with the different doses of the inhaled oligosaccharides, 30 minutes before the antigen challenge and then on experiment day 3 , the $\mathrm{PD}_{400}$ was re-determined. The doses of oligosaccharides used were: (a) oligosaccharide mixture $0.5 \mathrm{mg} / \mathrm{kg}$; (b) octasaccharide, $0.5 \mathrm{mg} / \mathrm{kg}$; 
(c) hexasaccharide, $0.125 \mathrm{mg} / \mathrm{kg}$; (d) tetrasaccharide, $0.03 \mathrm{mg} / \mathrm{kg}, 0.06 \mathrm{mg} / \mathrm{kg}$ and $0.125 \mathrm{mg} / \mathrm{kg}$.

Post-Antigen Administration of Tetrasaccharide $(n=5)$ To evaluate the effect of "post-antigen" administration of tetrasaccharide on LAR and AHR, the 3-day protocol described above was repeated, except that instead of pretreating the animals, the doses of tetrasaccharide $(0.03$ $\mathrm{mg} / \mathrm{kg} ; 0.06 \mathrm{mg} / \mathrm{kg} ; 0.125 \mathrm{mg} / \mathrm{kg}$ ) were administered immediately after the post-antigen measurements of $\mathrm{SR}_{\mathrm{L}}$. C. Agonist-Induced Bronchoconstriction ( $n=3)$

After obtaining the baseline measurements of $\mathrm{SR}_{\mathrm{L}}$, the sheep were challenged with aerosolized carbachol (10 breaths of $2 \%$ solution; $n=3$ ) histamine (50 breaths of $5 \%$ solution; $\mathrm{n}=3$ ) or leukotriene $(\mathrm{LT}) \mathrm{D}_{4}$ (20 breaths of $0.01 \%$ solution; $\mathrm{n}=3$ ) and measurements of $\mathrm{SR}_{\mathrm{L}}$ were repeated immediately after. On separate days, the sheep were pretreated with inhaled tetrasaccharide $(0.125 \mathrm{mg} /$ kg) 30 minutes before agonist challenge and then the above protocols were repeated.

\section{Histamine Release in BAL $(n=6)$}

In each animal BAL was performed on two different experiment days, at least two weeks apart, before and after a segmental antigen-challenge, without and after pretreatment with inhaled tetrasaccharide $(0.125 \mathrm{mg} / \mathrm{kg})$. Tetrasaccharide was nebulized 30 minutes before the segmental antigen challenge. Ascaris suum antigen $(2.5 \mathrm{ml}$ Ascaris suum and $2.5 \mathrm{ml}$ buffer) was infused via a wedged bronchoscope and BAL was performed 20 minutes later. The BAL effluent was centrifuged and the supernatant saved and frozen at $-80^{\circ} \mathrm{C}$ for subsequent RIA.

\section{Murine Studies}

The mice were immunized with intraperitoneal injection of ovalbumin $(0.2 \mathrm{ml}$ of $0.05 \%$ solution) on day 1 and again on day 14 . On days 25,26 and 27 , the negative control group $(n=4)$ received an aerosol of normal saline, while the positive control group $(n=5)$ was challenged with an aerosol of $3 \%$ ovalbumin for 30 minutes. On day 28 , the mice were sacrificed and BAL and lung tissue were prepared for estimation of eosinophil influx and airway inflammation. For the treatment group $(\mathrm{n}=4)$, the mice were pretreated with aerosolized tetrasaccharide $(0.3 \%$ solution) on days 25,26 , and 27 , one hour before ovalbumin challenge, and the above mentioned day 28 protocol was repeated. Histological specimens were obtained from one mouse in each group for representative purposes only.

\section{Statistical Analysis}

The data were expressed as mean $\pm \mathrm{SE}$. The $\mathrm{SR}_{\mathrm{L}}$ data were analyzed by a two-way analysis of variance with repeated measures, followed by Newman-Keuls pairwise comparison. Area Under the Curve for EAR AUC 0-4 and LAR AUC 4- $8_{\mathrm{h}}$ were calculated using the trapezoid rule for the treatment and control arms in the same animals and compared using a paired t-test. The baseline values of $\mathrm{PD}_{400}$ were compared to post-antigen $\mathrm{PD}_{400}$ (without and with oligosaccharide) by Friedman's two-way Analysis of Variance followed by non-parametric multiple comparison. Histamine concentration in the sheep BAL was analyzed by a paired t-test. Mouse BAL celluar analysis was first analyzed with a one way analysis of variance followed by Student-Newman-Keuls method to detect pairwise differences. Significance was accepted at $\mathrm{P}<0.05$.

\section{Results}

Effect of Heparin Oligosaccharides in Acute Responders

In acute responders $(n=6)$, mean $\pm S E$ peak $S R_{L}$ increased by $263 \pm 45 \%$ with antigen alone. We first tested the oligosaccharide mixture to insure that it had anti-allergic activity similar to what we had seen previously with ultra low molecular weight heparins [21,22]. The inhaled oligosaccharide mixture (MW:1930 daltons) significantly attenuated the peak antigeninduced bronchoconstrictor response (ABR) by $51 \pm$ $10 \%, 49 \pm 9 \%$ and $67 \pm 7 \%$ at doses of $0.25 \mathrm{mg} / \mathrm{kg}$, $0.5 \mathrm{mg} / \mathrm{kg}$ and $1 \mathrm{mg} / \mathrm{kg}$, respectively (Figure 1).

Dose response studies with various fractions, isolated from the heparin-oligosaccharide mixture, showed that octasaccharide was the least potent compared to hexasaccharide and tetrasaccharide which were equipotent at the doses tested (Figure 1). The octasaccharide fraction $(\mathrm{n}=5, \mathrm{MW}: 2480$ daltons) attenuated the ABR by $32 \pm$ $8 \%(\mathrm{P}=\mathrm{NS}), 61 \pm 11 \%(\mathrm{P}<.05)$, and $65 \pm 9 \%(\mathrm{P}<.05)$, at doses of $0.125 \mathrm{mg}, 0.25 \mathrm{mg} / \mathrm{kg}$ and $0.5 \mathrm{mg} / \mathrm{kg}$, respectively. The hexasaccharide fraction $(\mathrm{n}=5, \mathrm{MW}: 1890$ daltons) attenuated the ABR by $3 \pm 6 \%(\mathrm{P}=\mathrm{NS}), 69 \pm$ $10 \%(\mathrm{P}<.05)$, and $83 \pm 7 \%(\mathrm{P}<.05)$ at doses of 0.03 $\mathrm{mg} / \mathrm{kg}, 0.06 \mathrm{mg} / \mathrm{kg}$ and $0.125 \mathrm{mg} / \mathrm{kg}$, respectively. Similarly, the tetrasaccharide fraction ( $\mathrm{n}=5$, MW: 1231 daltons) attenuated the ABR by $26 \pm 8 \%(\mathrm{P}=\mathrm{NS}), 67 \pm 7 \%$ $(\mathrm{P}<.05)$ and $71 \pm 7 \%(\mathrm{P}<.05)$ at doses of $0.03 \mathrm{mg} / \mathrm{kg}$, $0.06 \mathrm{mg} / \mathrm{kg}$ and $0.125 \mathrm{mg} / \mathrm{kg}$, respectively. Based on these findings, we considered the $0.5 \mathrm{mg} / \mathrm{kg}, 0.125 \mathrm{mg} /$ $\mathrm{kg}$ and $0.125 \mathrm{mg} / \mathrm{kg}$ doses of octasaccharide, hexasaccharide and tetrasaccharide fractions, respectively to be most effective against ABR., At these doses, the octasaccharide fraction was two-fold more potent, and the tetrasaccharide and hexasaccharide fractions were eightfold more potent than the oligosaccharide mixture.

\section{Effect of Heparin Oligosaccharides in Dual Responders}

Having achieved significant inhibition of the ABR in acute responders, we next tested the activity of the oligosaccharides doses identified above in "Dual Responders". In this group $(n=6)$, antigen-induced changes in $\mathrm{SR}_{\mathrm{L}}$ without and after pretreatment with the inhaled heparin oligosaccharides are shown in figure 2. With 


\section{ACUTE RESPONDERS}
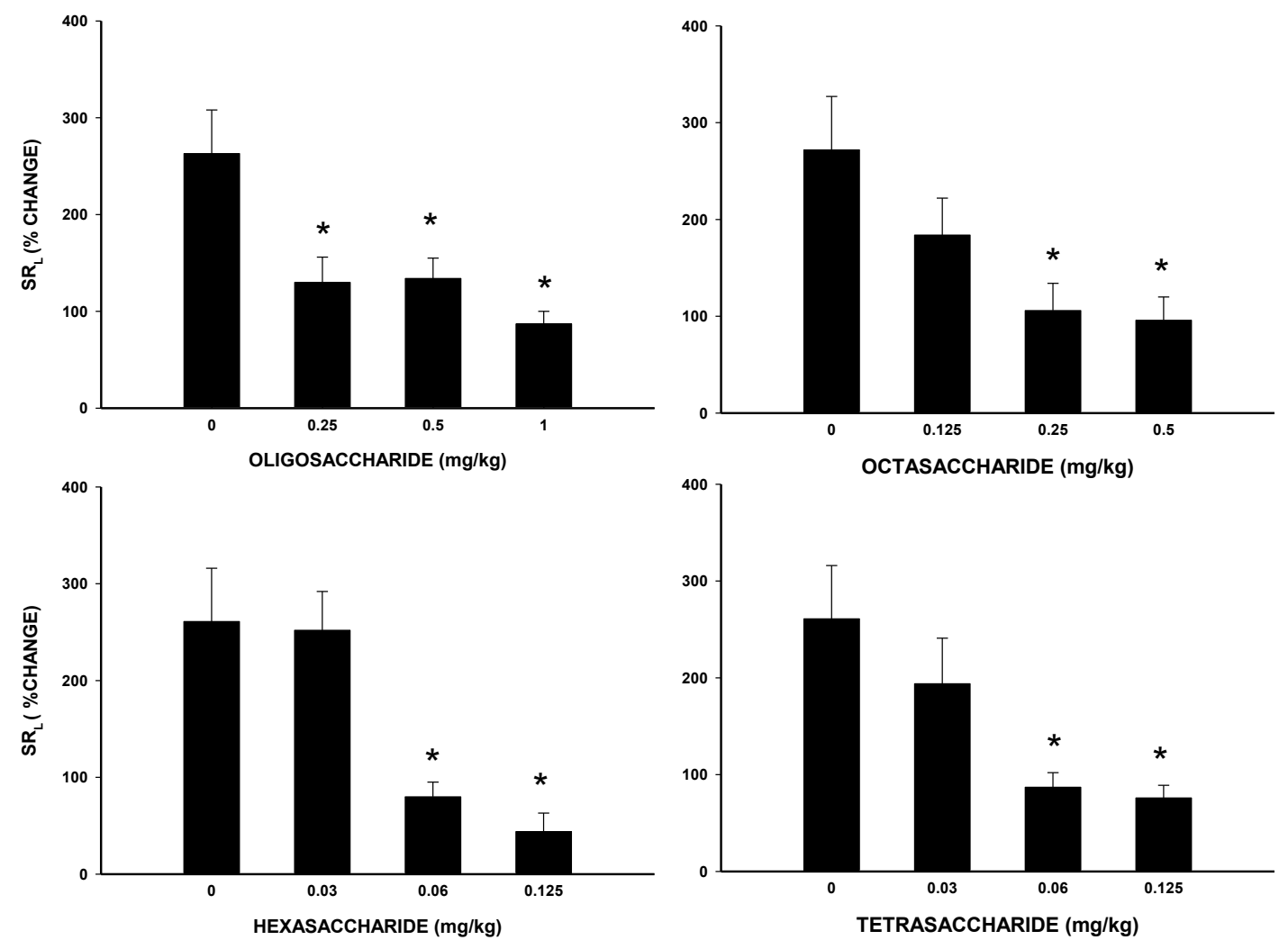

Figure 1 Effect of inhaled heparin-oligosaccharides on antigen-induced bronchoconstrictor response in "Acute Responder" sheep. Data are shown as \% change in specific lung resistance $\left(S R_{L}\right) \pm S E$ without and after pretreatment with different dose of oligosaccharide mixture $(n=$ 6) and various fractions including octasaccharide $(n=5)$, hexasaccharide $(n=5)$ and tetrasaccharide $(n=5)$. *Significantly different from antigen control $(P<.05)$.

antigen alone, peak early and late increases in $\mathrm{SR}_{\mathrm{L}}$ were $353 \pm 74 \%$ and $190 \pm 30 \%$, respectively. The corresponding early response area under the curve (EAR $\mathrm{AUC}_{0-4 \mathrm{~h}}$ ) and late response area under the curve (LAR AUC $_{4-8 \mathrm{~h}}$ ) were $577 \pm 132 \%$ and $353 \pm 73 \%$, respectively. Pretreatment with the inhaled oligosaccharide mixture $(0.5 \mathrm{mg} / \mathrm{kg})$ inhibited the antigen-induced increases in $\mathrm{SR}_{\mathrm{L}}$. Peak early and peak late increases in $\mathrm{SR}_{\mathrm{L}}$ with pretreatment were $140 \pm 21 \%$ and $77 \pm 19 \%$, respectively $(\mathrm{P}<.05)$. This translated to an inhibition of EAR AUC $\mathrm{A-}_{0}$ $4 \mathrm{~h}$ and LAR AUC ${ }_{4-8 \mathrm{~h}}$ by $60 \pm 15 \%$ and $52 \pm 8 \%$, respectively $(\mathrm{P}<.05$, Figure 2$)$. Heparin-derived oligosaccharide mixture also inhibited the antigen-induced AHR. In the control trial, the 24 hours post-antigen, mean $\pm \mathrm{SE}$ $\mathrm{PD}_{400}$ decreased from $19 \pm 1$ breath units to $10 \pm 2$ breath units; this was prevented by the heparin oligosaccharide mixture $\left(\mathrm{PD}_{400}=20 \pm 4\right.$ breath units). $(\mathrm{P}<.05$, Figure 3).

The octasaccharide fraction of heparin $(\mathrm{n}=3 ; 0.5 \mathrm{mg} /$ $\mathrm{kg}$ ) inhibited the EAR AUC $0-4 \mathrm{~h}$ by $74 \pm 10 \%$ and LAR $\mathrm{AUC}_{4-8 \mathrm{~h}}$ by $75 \pm 2 \%(\mathrm{P}<.05)$; while the antigen- induced AHR was inhibited by $100 \pm 7 \%$, $(\mathrm{P}<.05)$. The hexasaccharide fraction $(\mathrm{n}=5 ; 0.125 \mathrm{mg} / \mathrm{kg})$ inhibited

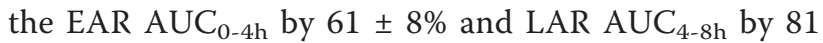
$\pm 6 \%(\mathrm{P}<.05)$; while antigen-induced AHR was inhibited by $80 \pm 13 \%(\mathrm{P}<.05)$; respectively. The anti-allergic activity of the tetrasaccharide fraction $(\mathrm{n}=5 ; 0.125 \mathrm{mg} /$ $\mathrm{kg}$ ) was comparable to the hexasaccharide fraction (Figure 2,3). Figure 4 shows that the anti-allergic activity of the tetrasaccharide fraction was dose-dependent. While $0.03 \mathrm{mg} / \mathrm{kg}(\mathrm{n}=5)$ dose was ineffective, the 0.06 $\mathrm{mg} / \mathrm{kg}(\mathrm{n}=6)$ and $0.125 \mathrm{mg} / \mathrm{kg}(\mathrm{n}=5)$ doses inhibited the EAR AUC ${ }_{0-4 h}$ by $47 \pm 13 \%$ and $63 \pm 11 \%(\mathrm{P}<.05)$; LAR AUC ${ }_{4-8 h}$ by $63 \pm 7 \%$ and $81 \pm 9 \%(\mathrm{P}<.05)$. Antigen-induced AHR at these doses was inhibited by $95 \pm$ $9 \%$ and $100 \pm 10 \%(\mathrm{P}<.05)$; respectively.

\section{Post-antigen administration of Tetrasaccharides}

Inhaled tetrasaccharide $(\mathrm{n}=5)$ caused a dose-dependent inhibition of LAR AUC ${ }_{4-8 \mathrm{~h}}$ and AHR when administered "after" the antigen challenge (Figure 5). While $0.03 \mathrm{mg} / \mathrm{kg}$ dose was ineffective, post-antigen administration of $0.06 \mathrm{mg} / \mathrm{kg}$ tetrasaccharide inhibited the $\mathrm{LAR} \mathrm{AUC}_{4-8 \mathrm{~h}}$ 


\section{DUAL RESPONDERS}
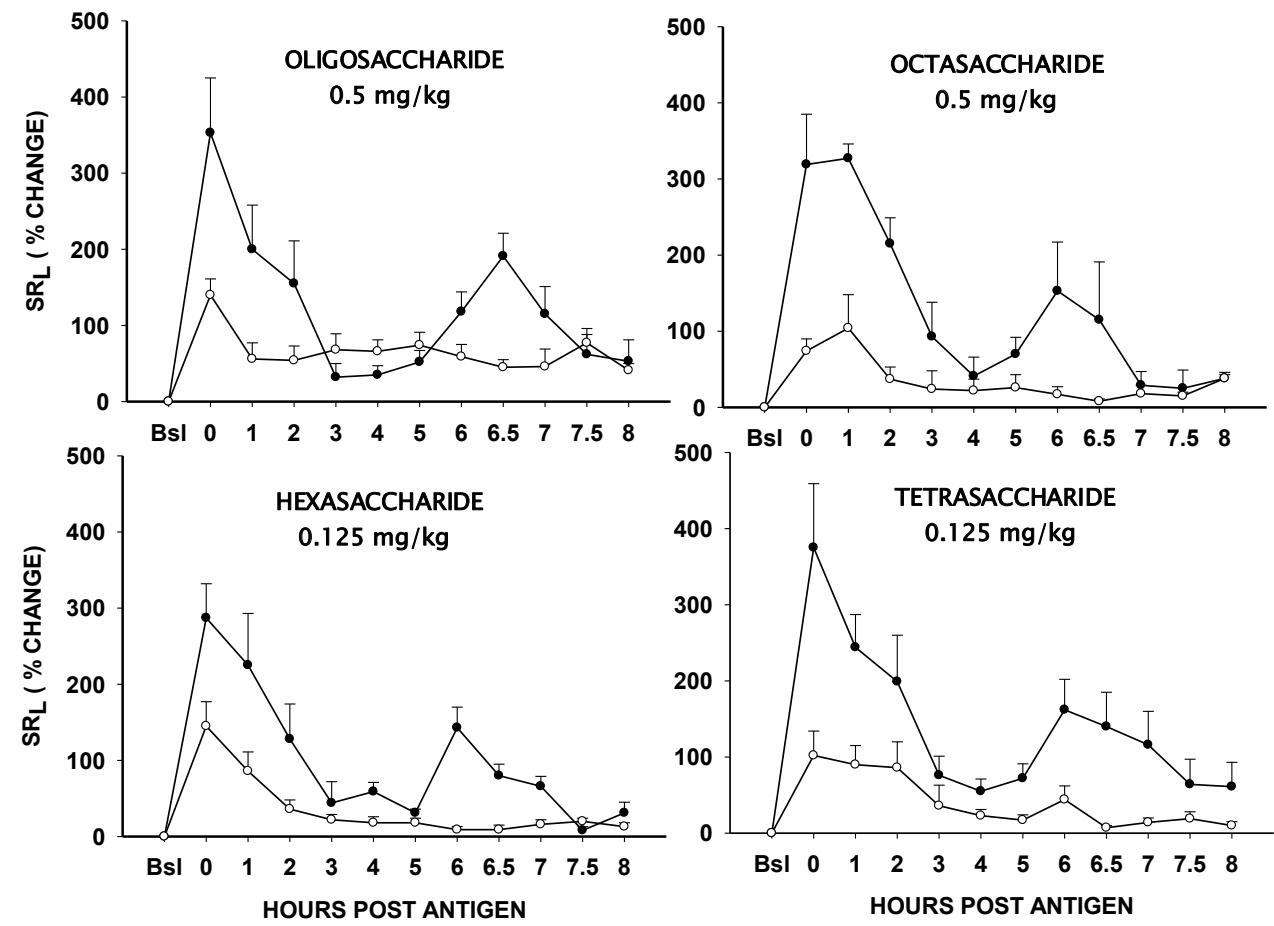

Figure 2 Effect of inhaled heparin oligosaccharides on antigen-induced early and late airway responses (EAR and LAR) in "Dual Responder" sheep. Data are shown as \% change in specific lung resistance $\left(S R_{L}\right) \pm$ SE without (solid circles) and after (open circles) pretreatment with oligosaccharide mixture $(n=6 ; 0.5 \mathrm{mg} / \mathrm{kg})$, and various fractions including octasaccharide $(n=3 ; 0.5 \mathrm{mg} / \mathrm{kg})$, hexasaccharide $(n=5 ; 0.125 \mathrm{mg} / \mathrm{kg})$, and tetrasaccharide $(n=5 ; 0.125 \mathrm{mg} / \mathrm{kg})$. Bsl = Baseline.
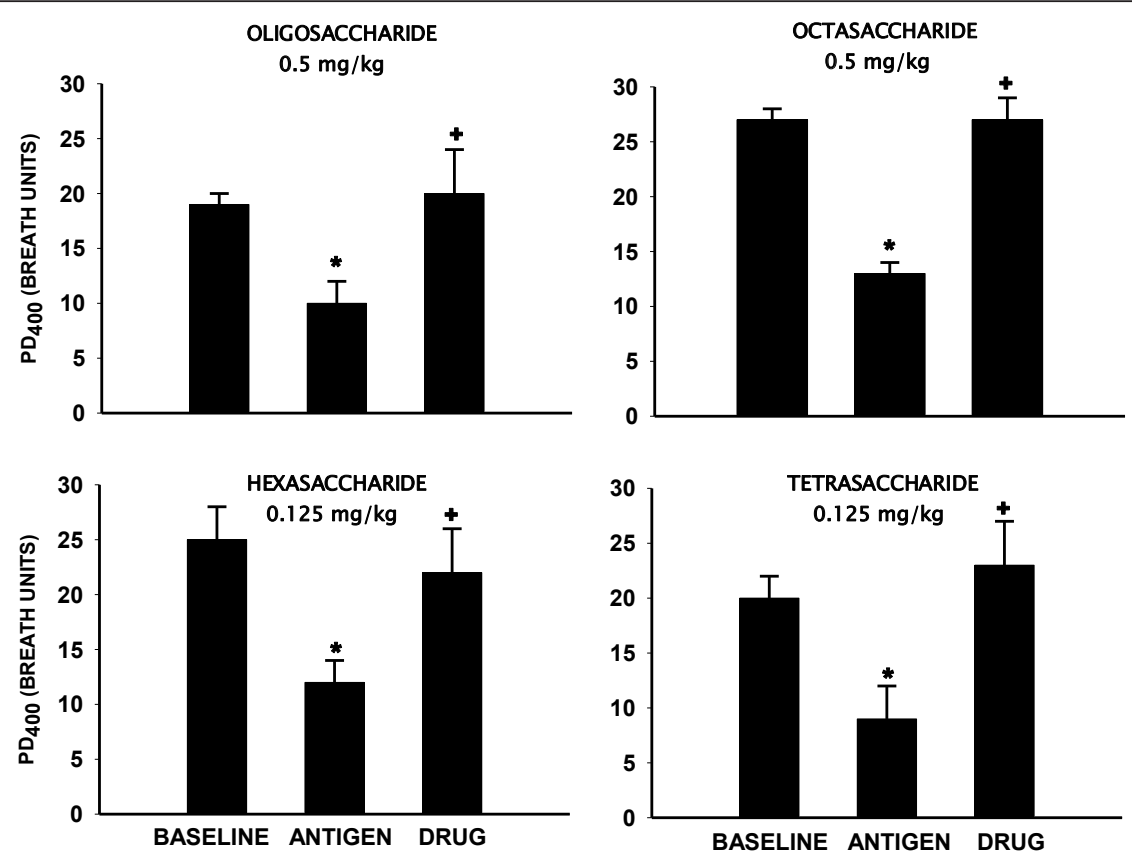

Figure 3 Effect of inhaled heparin oligosaccharides on antigen-induced airway hyperresponsiveness (AHR) in "Dual Responder" sheep Data are shown as $\mathrm{PD}_{400}$ (cumulative provocating dose of carbachol in breath units which increased $S R_{L}$ by $\left.400 \%\right) \pm S E$ for the baseline, and 24 hours post-antigen, without and after pretreatment with oligosaccharide mixture $(0.5 \mathrm{mg} / \mathrm{kg})$ and various fractions including Octasaccharide $(0.5$ $\mathrm{mg} / \mathrm{kg})$, hexasaccharide $(0.125 \mathrm{mg} / \mathrm{kg})$ and tetrasaccharide $(0.125 \mathrm{mg} / \mathrm{kg})$. ${ }^{*}$ Significantly different from baseline $(P<.05)$. + Significantly different from antigen control $(P<.05)$. 

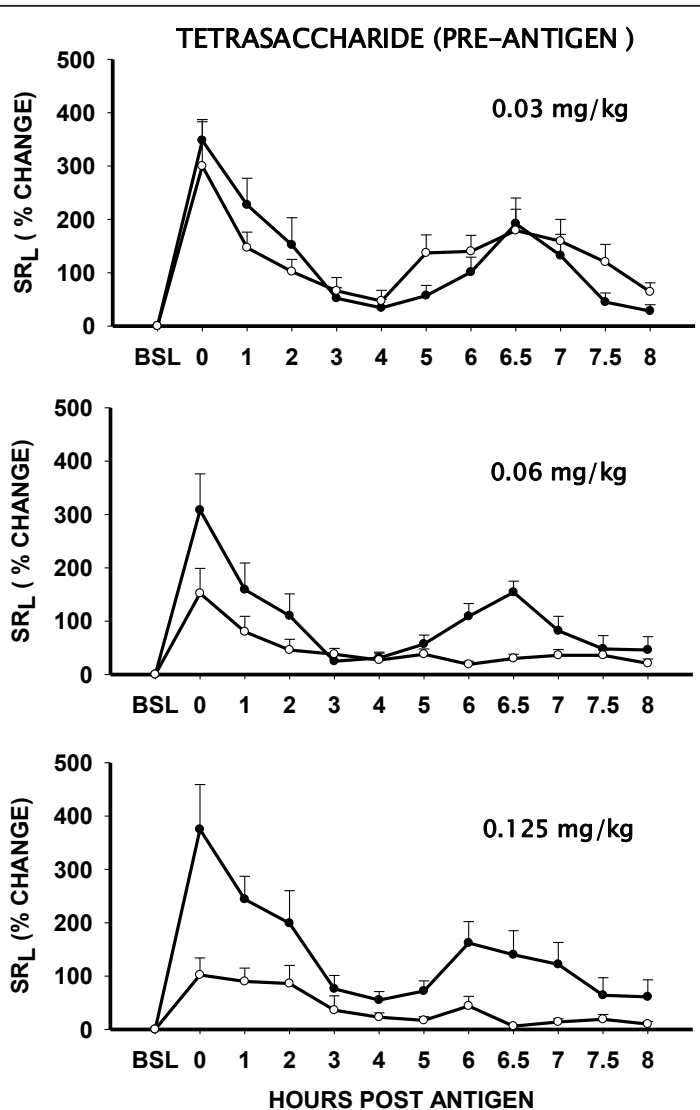

Figure 4 Dose response effect of pretreatment with inhaled heparin tetrasaccharide on antigen-induced early and late airway responses (EAR and LAR) in "Dual Responder" sheep. Data are shown as antigen-induced \% change in specific lung resistance $\left(S R_{L}\right) \pm$ SE without (solid circles) and after pretreatment (open circles) with inhaled tetrasaccharide (0.03 mg/kg, $n=5) ; 0.06 \mathrm{mg} / \mathrm{kg}, \mathrm{n}=6)$; and $0.125 \mathrm{mg} / \mathrm{kg}, \mathrm{n}=5$ ). BSL = Baseline.

and AHR by $80 \pm 9 \%$ and $100 \pm 16 \%(\mathrm{P}<.05)$, respectively. The effects of $0.06 \mathrm{mg} / \mathrm{kg}$ and $0.125 \mathrm{mg} / \mathrm{kg}$ doses of tetrasaccharide were comparable.

\section{Minimal effective chain length}

Heparin derived tetrasaccharide was the minimum effective chain length possessing the anti-allergic activity. The disaccharide fraction was ineffective in both "acute" and "dual" responder sheep. Inhaled disaccharide at a 32-fold higher dosage than tetrasaccharide had no effect on antigen-induced ABR in "acute responders" (Figure 6, Top). Similarly an 8-fold excess of disaccharide had no effect in dual responders (Figure 6, Bottom).

\section{Agonist-induced bronchoconstriction}

The inhaled tetrasaccharide fraction $(0.125 \mathrm{mg} / \mathrm{kg})$ failed to modify the bronchoconstrictor responses to histamine $(\mathrm{n}=3)$, carbachol $(\mathrm{n}=3)$ and $\mathrm{LTD}_{4}(\mathrm{n}=3)$. The mean \pm $\mathrm{SE} \mathrm{SR}$ L values without and after pretreatment with inhaled tetrasaccharide were $509 \pm 6 \%$ vs. $515 \pm 5 \%$ ( $\mathrm{P}=$ NS); $333 \pm 21 \%$ vs. $368 \pm 23 \%$ (P = NS); and $210 \pm 35 \%$
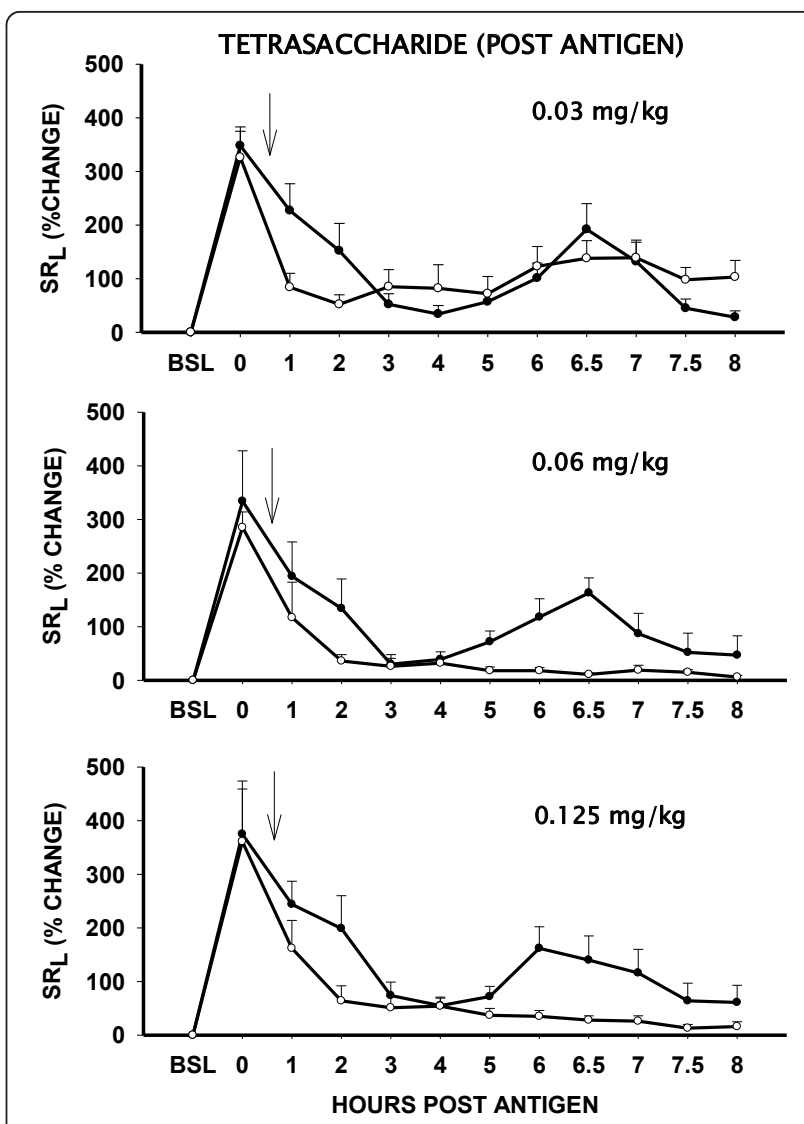

Figure 5 Dose response effect of inhaled heparin tetrasaccharide, administered "AFTER" the antigen challenge, on antigen-induced LAR. Data are shown as \% change in specific lung resistance $\left(S R_{L}\right) \pm S E$ without (solid circle) and after treatment (open circle) with various doses of tetrasaccharide $(n=5)$.

Tetrasaccharide was administered immediately after the postantigen measurement of $\mathrm{SR}_{\mathrm{L}}$ (Arrow). BSL = Baseline

vs. $222 \pm 19 \%(\mathrm{P}=\mathrm{NS})$ for histamine, carbachol and $\mathrm{LTD}_{4}$, respectively.

\section{Histamine Release in BAL}

Baseline concentration of histamine in BAL $(\mathrm{n}=6)$ was $0.4 \pm 0.2 \mathrm{nM}$ and $0.5 \pm 0.2 \mathrm{nM}$. Segmental antigen challenge caused a marked increase in BAL histamine concentration $(8.5 \pm 7.1 \mathrm{nM})$, which was not inhibited by pretreatment with inhaled tetrasaccharide $(9.8 \pm 8.1 \mathrm{nM})$.

\section{Antifactor Xa-activity}

In vitro the tetrasaccharide fraction had no anti-coagulant activity; the antifactor-Xa activity of tetrasaccharide fraction was 0.8 I.U.; while hexasaccharide and octasaccharide fractions had antifactor-Xa activity of 1.8 I.U. and 27 I.U., respectively.

\section{Murine Studies}

In ovalbumin immunized mice, aerosolized ovalbumin (+controls) produced a marked perivascular and peribronchial inflammatory response and caused a 


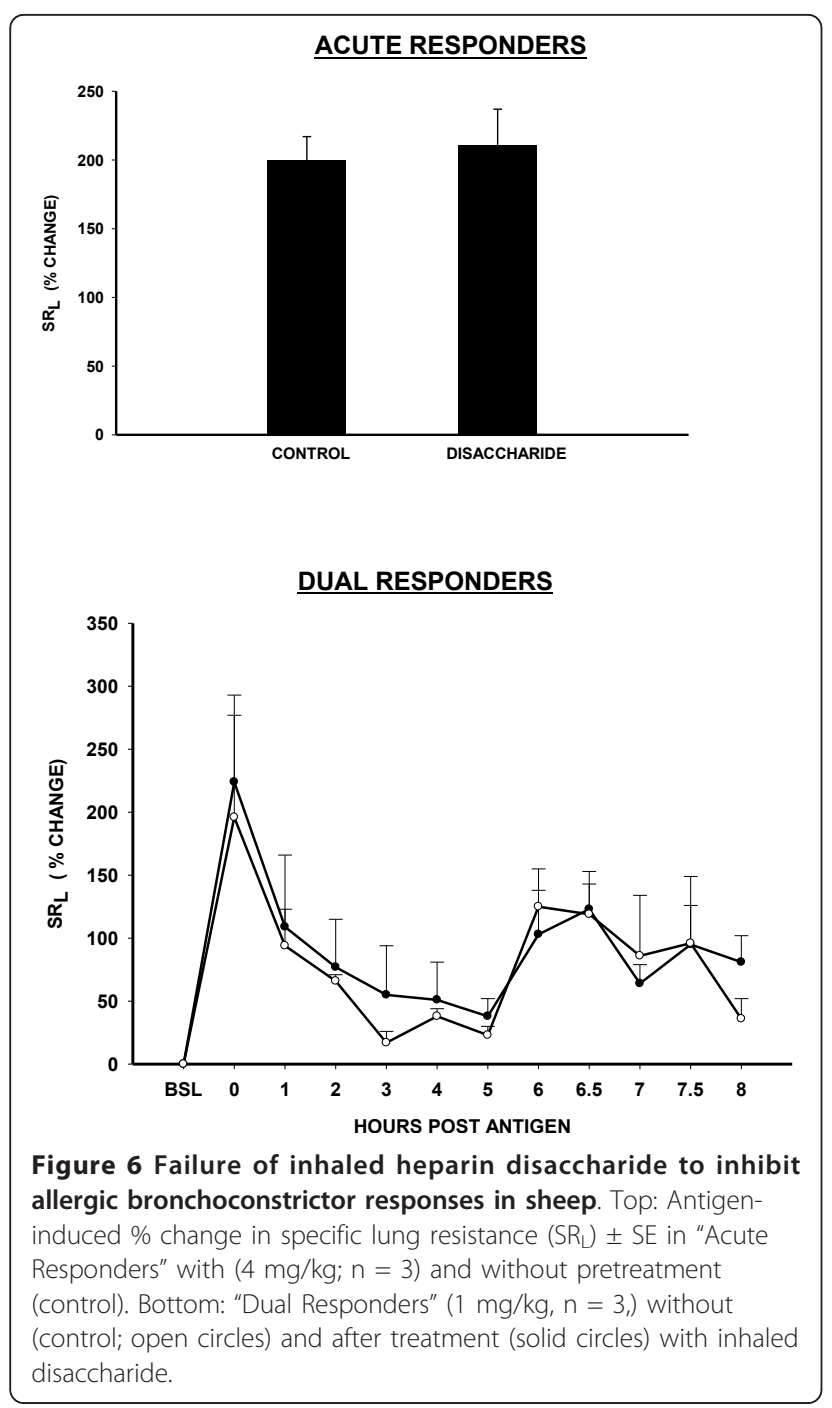

significant increase in total cells and eosinophils in the BAL compared to immunized but saline challenged animals (-controls, Table 1). Pretreatment with aerosolized heparin-tetrasaccharide in immunized and ovalbumin challenged mice inhibited the inflammatory response in the peribronchial and perivascular regions (Figure 7). This histological finding was supported by the data in Table 1, which shows that heparin tetrasaccharide pretreatment reduced the total number of cells by $41 \%$, the total number of eosinophils by $62 \%$ and the $\%$ eosinophils by $37 \%$ (all $\mathrm{P}<0.05$ ) when compared to the + controls. Table 1 also shows that there was a significant increase in the \% macrophages and \% neutrophils in the tetrasaccharide pretreated animals when compared to the + controls. However, calculation of the total neutrophil number shows the tetrasaccharide treated group $\left(0.06 \times 10^{6} \pm\right.$ $0.01)$ and the + control group $\left(0.06 \times 10^{6} \pm 0.02\right)$ not to be different.

\section{Chemical Structure Analysis}

Chemical structure analysis showed that the size-defined heparin-tetrasaccharide fraction is a mixture of tetrasaccharides. It predominantly consists of a pentasulfated tetrasaccharide (approximately 80\%), along with other tetrasaccharides that have fewer sulfate moieties. The pentasulfated tetrasaccharide has a molecular weight of 1231 daltons. Its chemical structure consists of 2-O-sulfo- $\mathrm{L}$ iduronic acid $(1 \rightarrow 4)$ 6-O, $N$-disulfo-D-glucosamine $(1 \rightarrow$ 4) 2-O-sulfo- L-iduronic acid $(1 \rightarrow 4$ ) 6-O-sulfo-2,5-Anhydro-D-Mannitol [IdoU2S $(1 \rightarrow 4)$ GlcNS6S $(1 \rightarrow 4)$ IdoU2S $(1 \rightarrow 4$ ) AMan-6S] (Figure 8).

\section{Discussion}

Many biological actions of heparin, including the antiallergic activity are molecular weight dependent [20-22].

Table 1 Effect of heparin tetrasaccharide on ovalbumin (OVA) induced changes in inflammatory cell influx in BAL of mice

\begin{tabular}{|c|c|c|c|c|c|c|c|c|}
\hline & $\begin{array}{l}\text { Total } \\
\text { Cells }\end{array}$ & $\begin{array}{l}\text { Total } \\
\text { Eosinophils }\end{array}$ & $\begin{array}{c}\% \\
\text { Eosinophils }\end{array}$ & $\begin{array}{c}\text { \% } \\
\text { Epithelial }\end{array}$ & $\begin{array}{c}\% \\
\text { Macrophages }\end{array}$ & $\begin{array}{c}\% \\
\text { Lymphocytes }\end{array}$ & $\begin{array}{c}\% \\
\text { Neutrophils }\end{array}$ & $\begin{array}{c}\% \\
\text { Monocytes }\end{array}$ \\
\hline \multirow{2}{*}{$\begin{array}{l}(-) \text { Control } \\
(\mathrm{n}=4)\end{array}$} & $0.46 \times 10^{6}$ & $0.8 \times 10^{3}$ & $0.2 \%$ & $1.1 \%$ & $94.2 \%$ & $3.1 \%$ & $0.2 \%$ & $1.2 \%$ \\
\hline & $(0.04)$ & $(0.3)$ & $(0.1)$ & (0.6) & (2.6) & (2.0) & $(0.1)$ & $(0.4)$ \\
\hline \multirow{2}{*}{$\begin{array}{l}(+) \text { Control } \\
(n=5)\end{array}$} & $* 1.02 \times 10^{6}$ & ${ }^{*} 0.45 \times 10^{6}$ & *44.3\% & $2.3 \%$ & $* 30.1 \%$ & $* 16.9 \%$ & $* 5.6 \%$ & $0.8 \%$ \\
\hline & $(0.15)$ & $(0.08)$ & $(6.0)$ & (1.1) & $(5.4)$ & $(2.1)$ & $(1.2)$ & $(0.5)$ \\
\hline \multirow{2}{*}{$\begin{array}{l}\text { Tetrasaccharide } \\
(\mathrm{n}=4)\end{array}$} & $+0.60 \times 10^{6}$ & $t^{*} 0.17 \times 10^{6}$ & $+* 27.7 \%$ & $3.7 \%$ & $\dagger^{*} 42.8 \%$ & *12.4\% & $\dagger * 9.5 \%$ & $1.1 \%$ \\
\hline & $(0.01)$ & $(0.01)$ & (0.9) & (1.3) & (3.5) & (1.6) & (1.7) & $(0.2)$ \\
\hline
\end{tabular}

Data are shown as mean (SE).

(-) Control (OVA sensitized/saline challenge)

(+) Control (OVA sensitized/OVA challenge)

Tetrasaccharide (Treatment group/OVA challenge)

* $\mathrm{p}<.05$ from (-) control

$+\mathrm{p}<.05$ from $(+)$ control 

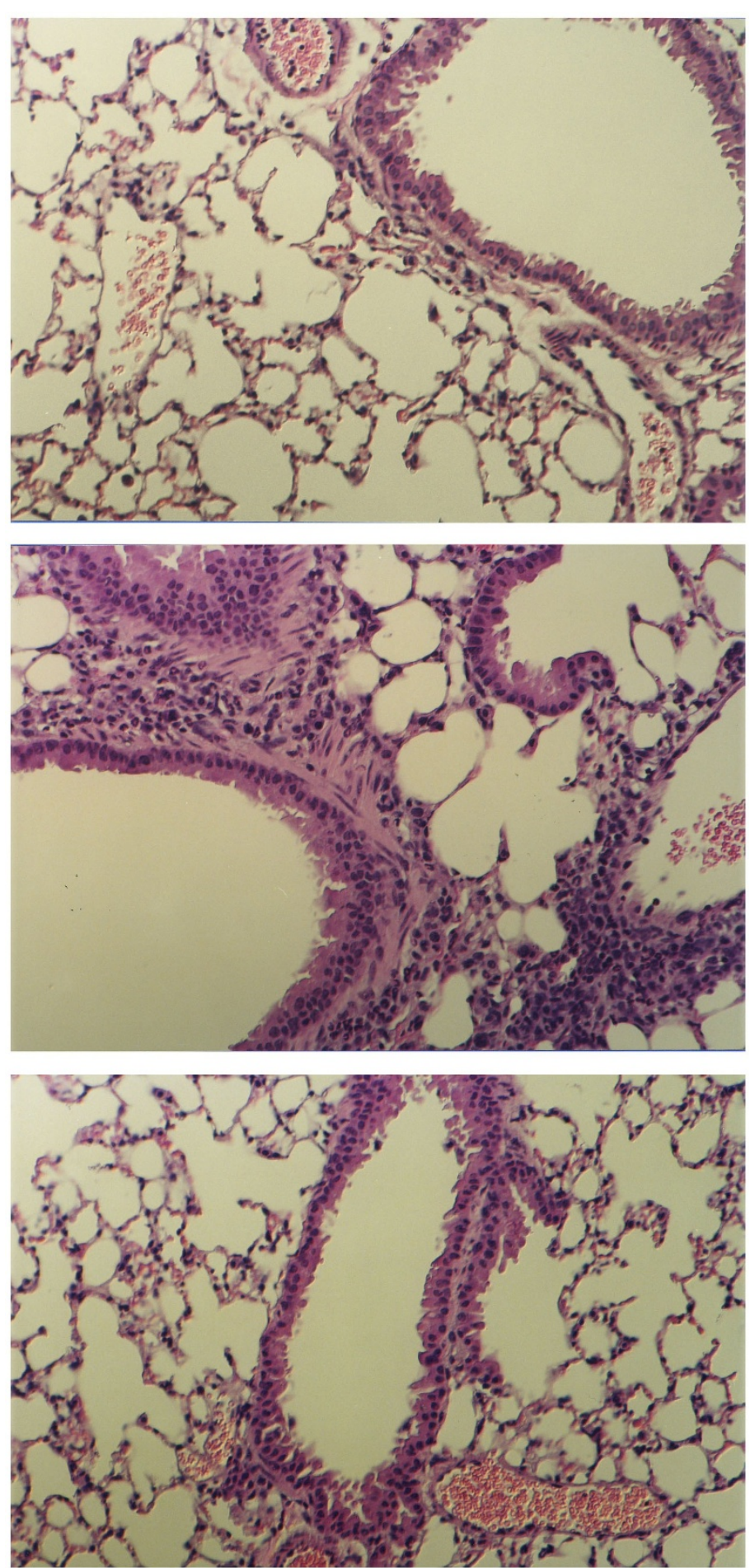

Figure 7 Lung histology samples in ovalbumin immunized mice. Top Panel: Control mice challenged with aerosolized saline; there is no evidence of peribronchial and perivascular inflammation. Middle Panel: Mice challenged with aerosolized ovalbumin; marked peribronchial and perivascular inflammation is seen with eosinophil infilteration. Bottom Panel: Ovalbumin challenged mice after pretreatment with nebulized heparin tetrasaccharide; reduced peribronchial and perivascular inflammation. Hematoxylin and eosin stain ( × 64 magnification). 


\section{PENTASULFATED TETRASACCHARIDE}

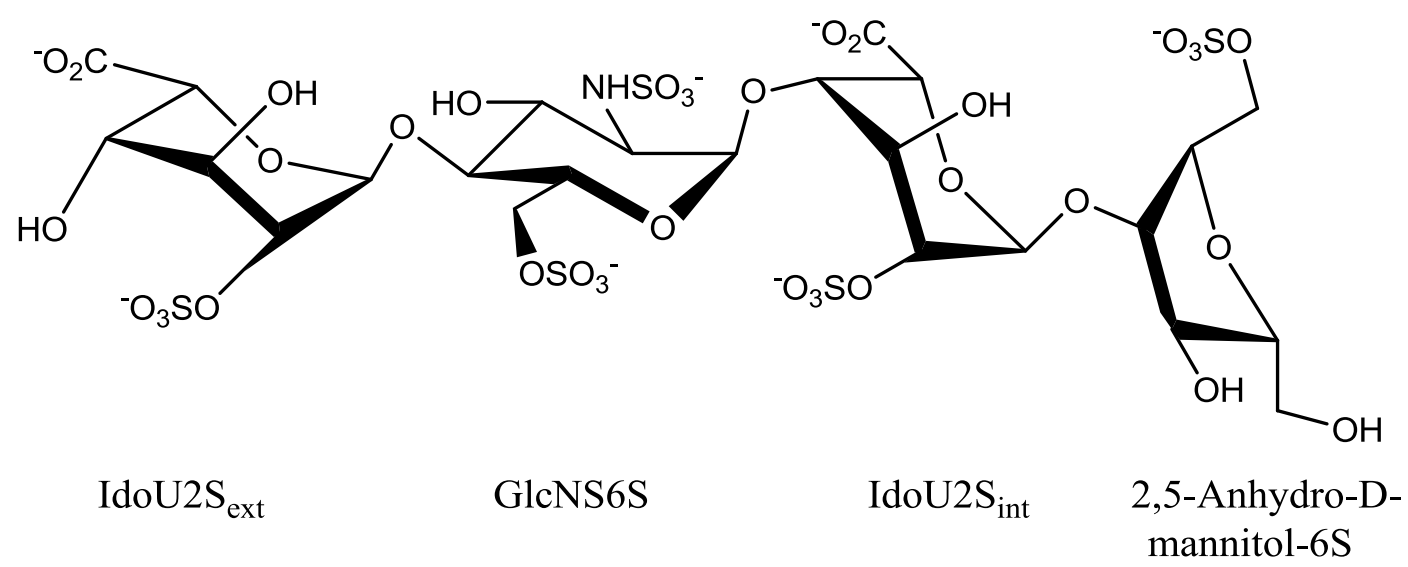

Figure 8 Chemical structure of heparin-derived pentasulfated tetrasaccharide.

Previous studies in sheep have demonstrated that unfractionated heparin inhibited the allergic airway responses only in "acute responders", while it was ineffective in "dual responders" [33]. In the "acute responder" sheep, the anti-allergic activity of fractionated heparin was molecular-weight dependent; and ultra low molecular weight heparin was found to be the most potent fraction $[21,22]$. We have also observed that the anti-allergic activity of fractionated heparin in the "dual responder" sheep is critically dependent on molecular weight. Only the ultra-low molecular weight heparin attenuated the antigen-induced EAR, LAR and AHR, while unfractionated heparin, medium molecular weight heparin and low molecular weight heparin were ineffective [23]. Thus, the ultra low molecular weight heparins (<2500 dalton) are qualitatively unique and inhibit allergic airway responses in both the acute and the dual responder sheep [21-23]. Although the anti-allergic activity of heparin is independent of its anticoagulant properties, the exact structural sequence and the chainlength possessing the anti-allergic activity is not known. The results of present study further extend our previous observations and demonstrate that: (a) the anti-allergic activity of heparin resides in a tetrasaccharide sequence, (b) the domains responsible for anticoagulant and antiallergic activity of heparin are distinctly different, and (c) heparin tetrasaccharide possesses anti-inflammatory properties.

The heparin-derived oligosaccharide mixture used in the present study attenuated the allergic airway responses in both "acute" and "dual" responder sheep (figure 1 and 2). Its average molecular weight is 1930 daltons, and its anti-allergic activity is comparable to other oligosaccharides (mol wt 2200-2400 daltons) studied previously [21-23]. The size exclusion chromatographic analysis of heparin-derived oligosaccharide mixture showed that it is a heterogenous mixture, consisting of disaccharide, tetrasaccharide, hexasaccharide, octasaccharide and some decasaccharide fractions. Our data with different fractions revealed that the minimal oligosaccharide chain length possessing anti-allergic activity was a tetrasaccharide as disaccharide was ineffective. The tetrasaccharide, hexasaccharide and octasaccharide fractions inhibited the allergic airway responses in both "acute" and "dual" responders in a dose-dependent manner; however, the relative potency of each oligosaccharide increased with the smaller fractions. In the "acute responders", the octasaccharide fraction was twofold more potent than the oligosaccharide mixture, while tetrasaccharide and hexasaccharide fractions were approximately eight-fold more potent. In the "dual responders", the anti-allergic activity of the octasaccharide fraction was comparable to the oligosaccharide mixture, while the hexasaccharide and the tetrasaccharide fractions were four-fold more potent. The results of this study also demonstrate that the tetrasaccharide fraction was also effective in inhibiting LAR and AHR, when administered after the antigen challenge. This action suggests possible anti-inflammatory activity as the LAR and AHR are pathophysiological indices of airway inflammation $[27,28]$. This conclusion is also supported by the mouse data (see below).

The heterogenous structure of glycosaminoglycan heparin is linked to its functional polydispersity. The biological activities of heparin are primarily mediated through its binding of various proteins and enzymes, 
but only the anti-thrombin III binding site involved in the anticoagulant action has been clearly elucidated as a distinct pentasaccharide sequence [25]. A hexasaccharide fraction has been suggested as the minimal chain length required to bind to fibroblast growth factor and transforming growth factor- $\beta$, as well as possessing antiproliferative activity on vascular smooth muscle cells $[4,5,7,6]$. The results of our studies demonstrate that heparin tetrasaccharide was the minimal chain length possessing the anti-allergic activity. Furthermore, the results of our studies are novel in that they demonstrate the unmasking of a biological action of heparin derived oligosaccharide (e.g. inhibition of LAR and AHR), which was not observed in unfractionated heparin or heparin fractions with molecular weight of $>2500$ daltons.

The basic structure of heparin consists of an alternating sequence of disaccharide units comprising of repeating $1 \rightarrow 4$ linked L-iduronic acid and $\mathrm{D}$-glucosamine residues, which are variably sulfated [3,2]. However, the fine structure of heparin disaccharide units and its sulfation pattern varies with the method of depolymerization. The heparin oligosaccharides used in this study were produced by controlled nitrous acid depolymerization of porcine heparin, resulting in terminal glucosamine ring contraction to 2,5-anhydro-mannose and followed by its reduction to 2,5-anhydro-mannitol moiety. The tetrasaccharide fraction predominantly consists of a pentasulfated tetrasaccharide with a molecular weight of 1231 daltons. Its chemical structure consists of IdoU2S $(1 \rightarrow$ 4) GlcNS6S $(1 \rightarrow 4)$ IdoU2S $(1 \rightarrow 4)$ AMan-6S. Besides 2-0 and 6-0 sulfation, it has $\mathrm{N}$-sulfation of the inner glucosamine ring, while the terminal glucosamine has ring contraction to 2,5-Anhydro-D-Mannitol-6S.

The anticoagulant action of heparin is predominantly mediated by binding of antithrombin III, which requires a pentasaccharide sequence with 3-0 sulfation of the inner glucosamine ring [25]. Previous studies in human subjects and sheep have suggested that the anti-allergic activity of inhaled heparin is independent of its anticoagulant properties, as APTT and antifactor-Xa activity were not prolonged $[15,17,18,16]$. This was also supported by the observations that non-anticoagulant fractions of heparin had potent anti-allergic activity $[22,23,34]$. The results of present study confirm this hypothesis. The heparin derived tetrasaccharide has an antifactor Xa activity of $0.8 \mathrm{IU}$; it also lacks critical 3-0 sulfation of the inner glucosamine ring, and its chain length is below the pentasaccharide sequence needed for anticoagulant activity. Collectively, these facts support the concept that the domains responsible for anti-coagulant and anti-allergic activity of heparin are distinctly different.

The mechanism of the anti-allergic activity of heparin derived oligosaccharides including the tetrasaccharide fraction is not known at present. Heparin derived tetrasaccharide failed to modify the bronchoconstrictor responses induced by the smooth muscle agonists, including histamine, carbachol or $\mathrm{LTD}_{4}$; thus excluding a direct effect on airway smooth muscle. The tetrasaccharide fraction had no effect on antigen-induced histamine release in BAL. It has been proposed that the antiallergic activity of unfractionated heparin in acute responders may be mediated by inhibition of $\mathrm{IP}_{3}$ dependent mast cell mediator release [35]. The inhibition of $\mathrm{IP}_{3}$ binding to its receptors by heparin is molecular weight dependent and the inhibitory activity decreases as the size of the heparin chain is reduced below 18 monosccharide units [36]. While fractions, containing 10-14 monosaccharide units, had substantially lower activity, the 8 monosaccharide fractions had none [36]. Thus, it is unlikely that the anti-allergic activity of heparin derived tetrasaccharide is related to inhibition of $\mathrm{IP}_{3}$-dependent mast cell mediator release. This is supported by our observation that the heparin derived tetrasaccharide failed to modulate antigen-induced histamine release in BAL fluid. The failure to modulate BAL histamine release but still have anti-allergic activity (blocking of EAR, LAR and AHR) is also consistent with our previous work which showed that structural domain of the heparin molecule responsible for this anti-allergic activity resides in the glycosaminoglycan chain length of $<2500$ daltons, whereas, the histamine-release inhibitory activity domain is located in the chain length of $>2500$ daltons $[22,23]$. As indicated above, all the fractions studied here were less $<2500$ daltons.

The unfractionated heparin and low molecular weight heparins have been suggested to possess anti-inflammatory properties [37-40]. The attenuation of allergic airway responses without inhibition of histamine released in the BAL suggests that the in vivo activity of heparin tetrasaccharide may be mediated by a yet unknown antiinflammatory mechanism. The inhibition of LAR and AHR by heparin tetrasaccharide, when administered after the antigen challenge supports this concept, as the immediate response to allergen is unimpaired, yet LAR and AHR, the primary physiological responses reflecting antigen-induced inflammation were blocked $[41,28]$. This concept is also supported by the observation that aerosolized heparin-tetrasaccharide caused a reduction in the allergen-induced eosinophil influx in the BAL fluid of ovalbumin sensitized mice and attenuated the peribronchial and perivascular inflammatory cell infiltration. The collective data supporting the anti-inflammatory actions of heparin tetrasaccharide seen here are consistent with reports that unfractionated heparin and heparin oligosaccharides, including tetrasaccharides, are effective inhibitors of L- P- selectins and demonstrate anti-inflammatory activity in vivo [42-44]. For example, 
intravenous heparin-tetrasaccharide was shown to reduce neutrophil influx in thioglycollate-induced peritoneal inflammation in mice [42], a process which has been shown to involve stimulation of both L- and P-selectin. Finally, the potential role of anti-selectin action of heparin tetrasaccharide in inhibiting allergic airway responses would also be consistent with our previous observation in sheep, showing attenuation of LAR and AHR by selectin inhibitors [45].

Although this study provides unique and novel data with regards to the anti-allergic and anti-inflammatory actions of oligosaccharides there are limitations. One short coming is that we are unclear as to the exact mechanism by which these oligosaccharides provide their protective effects. Having now described that the tetrasaccharide fraction is the minimal chain length to demonstrate these properties we can use this molecule to focus on the actual mechanism(s) involved in preventing these allergic responses. We should also point out that we did not measure the effects of these oligosaccharides on small airway function in this study. While our previous work has identified small airway dysfunction (i.e. decreased dynamic compliance) following allergen provocation [27], many of the studies designed to test the effects of agents on allergeninduced EAR, LAR and AHR have not involved these measures because $\mathrm{SR}_{\mathrm{L}}$ is more easily related to measures of airway function in patients in clinical trials (i.e. specific airway conductance or $\mathrm{FEV}_{1}$ ). Thus, while our data provides evidence that these oligosaccharides can modulate large airway effects associated with allergen challenge, we cannot categorically assume that small airway function was protected to a similar extent.

In conclusion, we have demonstrated for the first time that heparin tetrasaccharide is the minimal chain length that possesses anti-allergic and anti-inflammatory properties and these actions are distinct from any anti-coagulant properties. Our findings showing that both pre and post treatment modulate LAR and AHR, support the possibility that heparin oligosaccharides may interrupt multiple diverse cellular events involved in the complex cascade of allergic airway inflammation.

\footnotetext{
Abbreviations

AHR: airway hyperresponsiveness; ABR: antigen-induced bronchoconstrictor response; BAL: Bronchoalveolar Lavage; EAR: early airway response; LAR: late airway response; $E A R A \cup C_{0-4 h}$ : early response area under the curve; $L A R$ $A \cup C_{4-8 h}$ : late response area under the curve; $\mathrm{PD}_{400}$ : cumulative provocating dose of carbachol (in breath units) that increased $\mathrm{SR}_{\mathrm{L}}$ to $400 \%$ above the baseline; $\mathrm{SR}_{\mathrm{L}}$ : specific lung resistance; $\mathrm{SE}$ : standard error; $\mathrm{FEV}_{1}$ : forced expiratory volume in 1 second.
}

\section{Author details}

${ }^{1}$ Department of Research, Mount Sinai Medical Center, Miami Beach, Florida, USA. ${ }^{2}$ Endocyte Inc. West Lafayette, IN, USA.

\section{Authors' contributions}

TA and WMA designed the experimental studies, performed data analysis and wrote the manuscript. GS and IV isolated and characterized the different oligosaccharide fractions used in this study. All authors read and approved the final manuscript

\section{Competing interests}

T.A. is the inventor of US patents \#5,980,865 and \#6,193,957; assigned to OPKO HEALTH INC. He serves on the Scientific Advisory Board of OPKO HEALTH INC for which he receives stock options. None of the other authors have a financial relationship with a commercial entity that has an interest in the subject of this manuscript.

Received: 18 October 2011 Accepted: 23 January 2012

Published: 23 January 2012

\section{References}

1. Jacques LB: Heparin: an old drug with a new paradigm. Science 1979, 206:528-33.

2. Lindahl U: BioSynthesis of heparin and related polysaccharides. In Heparin, Chemical and Biological Properties, Clinical Applications. Edited by: Lane DA, Lindahl U. Boca Raton, FL: CRC Press; 1989:159-89.

3. Linhardt RJ, Heparin Loganathan D: Heparinoids and Heparin Oligosaccharides: Structure \& Biological Activities. In Biomimetic Polymers. Edited by: Gebelien CG. New York: Plenum Press; 1990:135-73.

4. Ishihara M, Takano R, Kanda T, Hayashi K, Hara S, Kikuchi H, Yoshida K. Importance of 6-O-sulfate groups of glucosamine residues in heparin for activation of FGF-1 and FGF-2. J Biochem 1995, 118:1255-60.

5. McCaffrey TA, Falcone DJ, Du B: Transforming growth factor-beta 1 is a heparin-binding protein: identification of putative heparin-binding regions and isolation of heparins with varying affinity for TGF-beta 1. J Cell Physiol 1992, 152:430-40.

6. Castellot JJ Jr, Cochran DL, Karnovsky MJ: Effect of heparin on vascular smooth muscle cells. I Cell metabolism J Cell Physiol 1985, 124:21-8.

7. Wright TC Jr, Castellot JJ Jr, Petitou M, Lormeau JC, Choay J, Karnovsky M Structural determinants of heparin's growth inhibitory activity. Interdependence of oligosaccharide size and charge. J Biol Chem 1989, 264:1534-42

8. Folkman J, Ingber DE: Angiogenesis: Regulatory role of heparin and related molecules. In Heparin. Edited by: Lane DA, Lindhal U. London Edward Arnold; 1989:317-33.

9. Schwartz $L B$, Bradford TR: Regulation of tryptase from human lung mast cells by heparin. Stabilization of the active tetramer. J Biol Chem 1986, 261:7372-9.

10. Ying QL, Kemme M, Saunders D, Simon SR: Glycosaminoglycans regulate elastase inhibition by oxidized secretory leukoprotease inhibitor. Am J Physiol 1997, 272:L533-L541.

11. Redini F, Tixier JM, Petitou M, Choay J, Robert L, Hornebeck W: Inhibition of leucocyte elastase by heparin and its derivatives. Biochem J 1988, 252:515-9.

12. Dolowtiz DA, Dougherty TF: The use of heparin as an anti-inflammatory agent. Laryngoscope 1960, 70:873-84.

13. Lider O, Mekori YA, Miller T, Bar-Tana R, Vlodavsky I, Baharav E, Cohen IR, Naparstek Y: Inhibition of T lymphocyte heparanase by heparin prevents T cell migration and T cell-mediated immunity. Eur J Immunol 1990, 20:493-9.

14. Weiler JM, Edens RE, Linhardt RJ, Kapelanski DP: Heparin and modified heparin inhibit complement activation in vivo. J Immunol 1992, 148:3210-5.

15. Ahmed T, Abraham WM, D'Brot J: Effects of inhaled heparin on immunologic and nonimmunologic bronchoconstrictor responses in sheep. Am Rev Respir Dis 1992, 145:566-70.

16. Ahmed T, Garrigo J, Danta I: Preventing bronchoconstriction in exerciseinduced asthma with inhaled heparin. N Engl J Med 1993, 329:90-5.

17. Garrigo J, Danta I, Ahmed T: Time course of the protective effect of inhaled heparin on exercise-induced asthma. Am J Respir Crit Care Med 1996, 153:1702-7.

18. Diamant Z, Timmers MC, Van der Veen H, Page CP, Van der Meer FJ, Sterk PJ: Effect of inhaled heparin on allergen-induced early and late asthmatic responses in patients with atopic asthma. Am J Respir Crit Care Med 1996, 153:1790-5. 
19. Bowler SD, Smith SM, Lavercombe PS: Heparin inhibits the immediate response to antigen in the skin and lungs of allergic subjects. Am Rev Respir Dis 1993, 147:160-3.

20. Laurent TC, Tengblad A, Thunberg L, Hook M, Lindahl U: The molecularweight-dependence of the anti-coagulant activity of heparin. Biochem $J$ 1978, 175:691-701

21. Martinez-Salas J, Mendelssohn R, Abraham WM, Hsiao B, Ahmed T: Inhibition of allergic airway responses by inhaled low-molecular-weight heparins: molecular-weight dependence. J App/ Physiol 1998, 84:222-8.

22. Campo C, Molinari JF, Ungo J, Ahmed T: Molecular-weight-dependent effects of nonanticoagulant heparins on allergic airway responses. J Appl Physiol 1999, 86:549-57.

23. Ahmed T, Ungo J, Zhou M, Campo C: Inhibition of allergic late airway responses by inhaled heparin-derived oligosaccharides. J Appl Physiol 2000, 88:1721-9.

24. Cifonelli JA: The relationship of molecular weight, and sulfate content and distribution to anticoagulant activity of heparin preparations. Carbohydr Res 1974, 37:145-54.

25. Lindahl U, Bäckström G, Thunberg L, Leder IG: Evidence for a 3-O-sulfated D-glucosamine residue in the antithrombin-binding sequence of heparin. Proc Natl Acad Sci USA 1980, 77:6551-5.

26. Abraham WM, Ahmed A, Cortes A, Sielczak MW, Hinz W, Bouska J, Lanni C, Bell RL: The 5-Lipoxygenase inhibitor zileuton blocks antigen-induced late airway responses, inflammation and airway hyperresponsiveness in allergic sheep. Eur J Pharm 1992, 217:119-26.

27. Abraham WM, Delehunt JC, Yerger L, Marchette B: Characterization of a late phase pulmonary response following antigen challenge in allergic sheep. Am Rev Respir Dis 1983, 128:839-44.

28. Abraham WM, Sielczak MW, Ahmed A, Cortes A, Lauredo IT, Kim J, Pepinsky B, Benjamin CD, Leone DR, Lobb RR, Weller PF: Alpha -integrins $^{-}$ mediate antigen-induced late bronchial responses and prolonged airway hyperresponsiveness in sheep. J Clin Invest 1994, 93:776-87.

29. Shively JE, Conrad HE: Formation of anhydrosugars in the chemical depolymerization of heparin. Biochem 1976, 15:3932-42.

30. Bienkowski MJ, Conrad HE: Structural characterization of the oligosaccharides formed by depolymerization of heparin with nitrous acid. J Biol Chem 1985, 260:356-65.

31. Gatti G, Casu B, Hamer GK, Perlin AS: Studies on the confirmation of heparin by ${ }^{1} \mathrm{H}$ and ${ }^{13} \mathrm{C}$ NMR Spectroscopy. Macromolecules 1979, 12:1001-7.

32. Mallis LM, Wang HM, Loganathan D, Linhardt RJ: Sequence analysis of highly sulfated, heparin-derived oligosaccharides using fast atom bombardment mass spectrometry. Anal Chem 1989, 61:1453-8.

33. Ahmed T, D'Brot J, Abraham WM, Lucio J, Mendelssohn R, Robinson MJ, Shakir S, SanPedro B: Heterogeneity of allergic airway responses in sheep: Differences in signal tranduction? Am J Respir Crit Care Med 1996, 154:843-9.

34. Ahmed T, Campo C, Abraham MK, Molinari JF, Abraham WM, Ashkin D, Syriste T, Andersson LO, Svahn CM: Inhibition of antigen-induced acute bronchoconstriction, airway hyperresponsiveness, and mast cell degranulation by a nonanticoagulant heparin -Comparison with a low molecular weight heparin. Am J Respir Crit Care Med 1997, 155:1848-55.

35. Ahmed T, Syriste T, Mendelssohn R, Sorace D, Mansour E, Lansing M, Abraham WM, Robinson MJ: Heparin prevents antigen-induced airway hyperresponsiveness: Interference with $\mathrm{IP}_{3}$-mediated mast cell degranulation. J Appl Physiol 1994, 76:893-901.

36. Tones MA, Bootman MD, Higgins BF, Lane DA, Pay GF, Lindahl U: The effect of heparin on the inositol 1,4,5-trisphosphate receptor in rat liver microsomes. Dependence on sulphate content and chain length. FEBS Lett 1989, 252:105-8.

37. Rao NV, Argyle B, Xu X, Reynolds PR, Walenga JM, Prechel M, Prestwich GD, MacArthur RB, Walters BB, Hoidal JR, Kennedy TP: Low anticoagulant heparin targets multiple sites of inflammation, suppresses heparininduced thrombocytopenia, and inhibits interaction of RAGE with its ligands. Am J Physiol Cell Physiol 2010, 299:C97-110.

38. Hochart $H$, Jenkins PV, Smith OP, White B: Low-molecular weight and unfractionated heparins induce a downregulation of inflammation: decreased levels of proinflammatory cytokines and nuclear factorkappaB in LPS-stimulated human monocytes. Br J Haematol 2006, 133:62-7.
39. Matzner $Y$, Marx G, Drexler R, Eldor A: The inhibitory effect of heparin and related glycosaminoglycans on neutrophil chemotaxis. Thromb Haemost 1984, 52:134-7.

40. Tyrrell DJ, Horne AP, Holme KR, Preuss JM, Page CP: Heparin in inflammation: potential therapeutic applications beyond anticoagulation. Adv Pharmacol 1999, 46:151-208.

41. O'Byrne PM, Dolovich J, Hargreave FE: State of Art: Late asthmatic responses. Am Rev Respir Dis 1987, 136:740-51.

42. Nelson RM, Cecconi O, Roberts WG, Aruffo A, Linhardt RJ, Bevilacqua MP: Heparin oligosaccharides bind L- and P-selectin and inhibit acute inflammation. Blood 1993, 82:3253-8.

43. Koenig A, Norgard-Sumnicht K, Linhardt R, Varki A: Differential interactions of heparin and heparan sulfate glycosaminoglycans with the selectins. Implications for the use of unfractionated and low molecular weight heparins as therapeutic agents. J Clin Invest 1998, 101:877-89.

44. Seeds EA, Hanss J, Page CP: The effect of heparin and related proteoglycans on allergen and PAF-induced eosinophil infiltration. J Lipid Mediat 1993, 7:269-78.

45. Abraham WM, Ahmed A, Sabater JR, Lauredo IT, Botvinnikova Y, Bjercke RJ, Hu X, Revelle BM, Kogan TP, Scott IL, Dixon RAF, Yeh ETH, Beck PJ: Selectin blockade prevents antigen-induced late bronchial responses and airway hyperresponsiveness in allergic sheep. Am J Respir Crit Care Med 1999, 159:1205-14.

doi:10.1186/1465-9921-13-6

Cite this article as: Ahmed et al.: Inhibition of allergic airway responses by heparin derived oligosaccharides: identification of a tetrasaccharide sequence. Respiratory Research 2012 13:6.

\section{Submit your next manuscript to BioMed Central and take full advantage of:}

- Convenient online submission

- Thorough peer review

- No space constraints or color figure charges

- Immediate publication on acceptance

- Inclusion in PubMed, CAS, Scopus and Google Scholar

- Research which is freely available for redistribution

Submit your manuscript at www.biomedcentral.com/submit
Biomed Central 